\title{
Sítios do Encontro: Arqueologia do entorno do Encontro das Águas
}

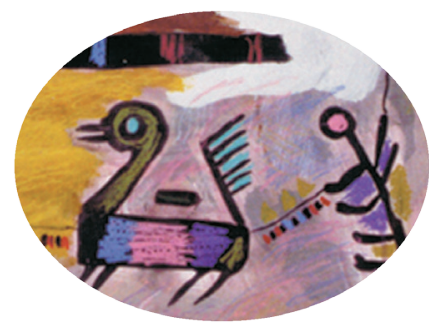

Helena Pinto Lima*

Carlos Augusto da Silva Bruno Marcos Moraes *

Manaus é uma das capitais brasileiras mais ricas em termos de patrimônio arqueológico pré-colonial. O alto potencial arqueológico da região é comprovado pelas dezenas de sítios ali presentes, principalmente na zona rural do município (HILBERT, 1968; SIMÕES, 1974; COSTA e LIMA, 2006). Em contexto plenamente urbano são conhecidos vinte e quatro sítios, em diferentes graus de preservação. No entanto, os sítios arqueológicos já conhecidos e cadastrados não refletem, amostralmente, a realidade. Eles representam uma pequena parcela dos sítios que efetivamente estão - ou estiveram - sob a cidade, muitas vezes já destruídos pelo ritmo desenfreado do crescimento urbano (LIMA e MORAES, 2010).

A ciência arqueológica tem historicamente buscado empreender a tarefa de contar essa história indígena local, a partir do registro arqueológico - em toda a sua potencial diversidade. Cabe salientar que a ausência de documentos escritos anteriores à colonização europeia, referentes a essas populações, tornam a arqueologia uma área de estudo-chave para que processos históricos e culturais dessas ocupações sejam compreendidos. O elevado potencial arqueológico da área é indiscutível diante dos sítios já encontrados (COSTA e

\footnotetext{
* Doutorado pelo Museu de Arqueologia e Etnologia da USP. Professora Visitante no PPG em Antropologia Social na Universidade Federal do Amazonas (UFAM) e pesquisadora associada ao Museu Amazônico (UFAM). Faz parte da Coordenação do Núcleo Regional Norte da Sociedade de Arqueologia Brasileira (SAB Norte).

** Graduado em Ciências Sociais pela Universidade de São Paulo, trabalha em arqueologia pré-colonial, especialmente na aplicação de geotecnologias em arqueologia.
} 
LIMA, 2006).

$\mathrm{Na}$ zona leste da cidade, nas margens do rio Negro e Amazonas, na área mundialmente conhecida pelo fenômeno do "Encontro das Águas", a ocorrência de sítios arqueológicos está intimamente ligada a essa paisagem natural e cultural - na medida em que populações habitaram, transformaram e simbolizaram de diferentes maneiras o ambiente, em temporalidades distintas.

Atualmente, a zona leste é uma região administrativa da prefeitura de Manaus que engloba bairros com histórico de ocupação e situação socioeconômica bastante diversa. Como um todo, é a região que possui o maior centro comercial da cidade, além de ser a região mais populosa da capital, como os bairros São José, Jorge Teixeira, Zumbi e Armando Mendes. Nessa mesma região situa-se o mais famoso atrativo turístico da cidade, o fenômeno do Encontro das Águas. No entanto, pequena ou nenhuma parcela dessa intensa atividade turística, que move milhares de reais todos os anos, traz benefícios diretos para a população que vive no local. O processo de tombamento pelo Instituto do Patrimônio Histórico e Artístico Nacional (Iphan) se coloca como uma importante forma de proteger e valorizar esse importante sítio paisagístico, ambiental, arqueológico e geológico, e também cultural.

A arqueologia local sugere uma ocupação que pode remontar milhares de anos atrás, como no caso do sítio rupestre Ponta das Lajes. Os sítios cerâmicos somam quase uma dezena e apontam para sequência de uma ocupação, aparentemente ininterrupta, desde o início da era cristã até o contato com o europeu e os dias atuais (LIMA et. al., 2006; LIMA, 2008; NEVES, 2006, 2008). Dentre os artefatos encontrados nesses locais, os recipientes cerâmicos remetem a diferentes períodos e estilos, e incluem diversas utilidades, entre elas a funerária. As chamadas fases Açutuba, Manacapuru e Paredão, da Tradição Borda Incisa, e a fase Guarita, da Tradição Policroma da Amazônia, traduzem os conjuntos arqueológicos cerâmicos à linguagem dos cientistas, constituindo a cronologia de ocupação da área (Idem, ibidem, HILBERT, 1968; MEGGERS e EVANS, 1961, 1983).

Mais recentemente, as pesquisas arqueológicas realizadas no âmbito do Projeto Amazônia Central (MAE/USP) e pelo Museu Amazônico (Ufam) têm colocado em evidência não somente a antiguidade da ocupação local, mas também sua diversidade. As maneiras pelas quais como o homem pretérito 
interagiu com o ambiente tropical, levando, por exemplo, à formação das Terras Pretas de Índio, que são solos antropogênicos muito férteis, têm sido alvo prioritário de investigação (PETERSEN et. al., 2001; NEVES, 2006, 2008). Finalmente, o reconhecimento de que as paisagens amazônicas atuais são frutos de milhares de anos de intenso manejo ambiental, levam as discussões sobre a sustentabilidade a novos rumos e colocam a arqueologia e o conhecimento arqueológico em evidência.

Dentro desse contexto, o sítio Lajes (AM-MA-01) se coloca como relevante. A importância do sítio para o contexto da arqueologia da cidade é indubitável: trata-se do primeiro sítio arqueológico de Manaus registrado junto ao Cadastro Nacional de Sítios Arqueológicos (CNSA) do Iphan. Trabalhos recentes de avaliação de impacto e resgate arqueológico realizados em Lajes renderam uma coleção composta por grandes urnas funerárias e vasos cerâmicos, além de inúmeros fragmentos, que trouxeram importantes informações sobre a ocupação desta região como um todo, que certamente foi densamente ocupada durante o final primeiro milênio d.C., entre os séculos 6 e 12. Ainda, o local se configura como um sítio histórico ao guardar evidências materiais do processo de apropriação pós-colonial da área, principalmente do início do século passado. As ruínas de olaria ali existentes testemunham essa história (LIMA e MORAES, 2010).

O Lajes, cadastrado no CNSA-Iphan sob a insígnia de AM-MA-01, foi o primeiro sítio arqueológico registrado no município de Manaus. O histórico de pesquisas do sítio arqueológico em questão se inicia com sua identificação e o cadastramento preliminar de suas informações, feitos pelo arqueólogo M. Simões, ainda na década de 70, em suas investigações ao longo dos rios Negro e Solimões (SIMÕES \& ARAÚJO-COSTA, 1978). Após um período de ausência de pesquisas arqueológicas, pesquisadores ligados ao Projeto Amazônia Central (PAC) revisitaram o sítio em 2006 por ocasião do Levantamento Arqueológico do Município de Manaus - Lama (COSTA \& LIMA, 2006), quando então foram identificadas nove urnas que afloravam na superfície do local. Novas pesquisas arqueológicas se deram, em 2009-2010, pela equipe do Museu Amazônico, por ocasião da implantação do Programa de Ampliação do Abastecimento de Água de Manaus (Proama), quando a maior parte do sítio arqueológico foi destruída.

Esse sítio localiza-se a leste do núcleo urbano mais denso da cidade de 
Manaus, no topo de um terraço fluvial nas margens do rio Negro, de frente ao Encontro das Águas. Caracteriza-se pela presença de solo antropogênico (Terras Pretas de Índio) e de grandes recipientes cerâmicos. Os vestígios escavados do sítio, os recipientes inteiros em particular, remetem à ocupação dos produtores das cerâmicas da fase Paredão, Tradição Borda Incisa. Aparentemente, o setor do sítio, onde foram escavados esses recipientes, possuía uma função funerária, a julgar pelo tamanho dos recipientes e por sua localização no estrato subsuperficial, abaixo da camada de terra preta. A própria disposição dos recipientes - tendo um recipiente de maiores dimensões ao centro (Figura 1 e 2) e diversos outros ao seu redor - pode aludir também a esse contexto funerário. No entanto, dos dois recipientes escavados em laboratório até o momento, apenas um apresentou vestígios ósseos.

É importante ressaltar também que, mais do que um sítio pré-colonial cronologicamente distante, o sítio Lajes também conta parte de uma história econômica presente da história de Manaus. As estruturas ainda presentes da olaria Irca também constituem patrimônio cultural ao serem remanescentes materiais de um período inicial de uma fase econômica hoje bastante presente e atuante no Estado: a produção de cerâmica industrial. Portanto, o sítio conta uma história (de longa e curta duração) da cidade de Manaus e da população que nela habita (Figuras 3 e 4).
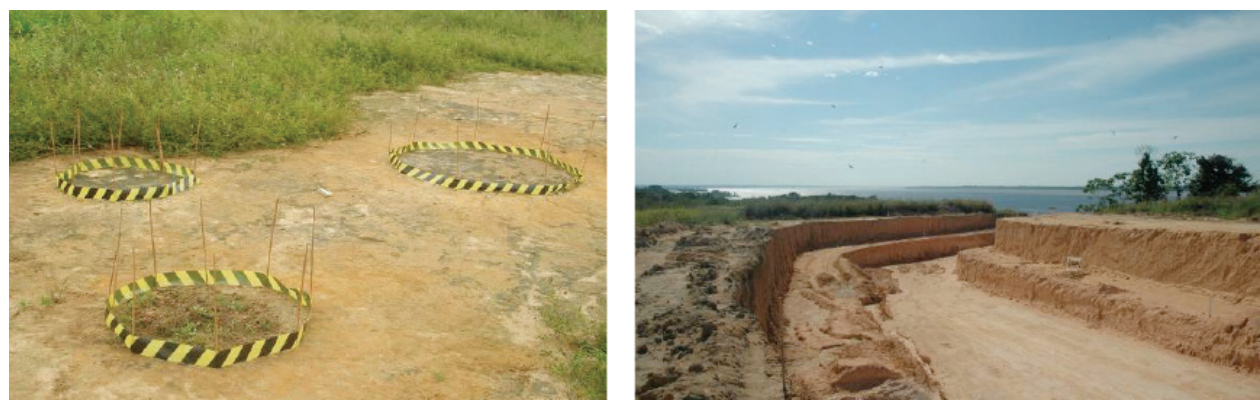

Figura 1 e 2 - Recipientes encontrados em 2006 (Foto: Lama); vala criada no mesmo local para implantação de tubos para captação de água (Foto: C. Moraes, 2010). 

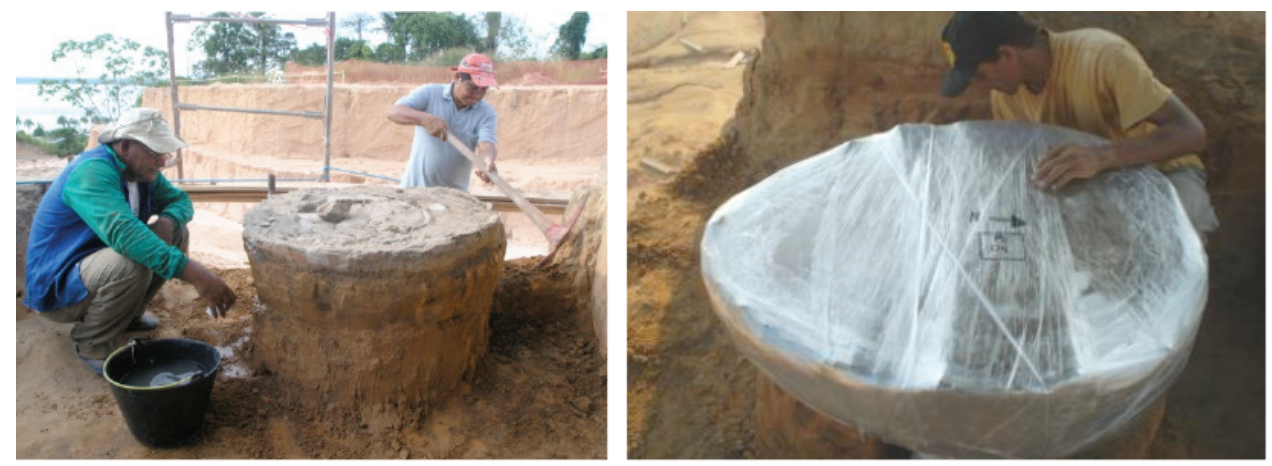

Figuras 3 e 4 - Escavação de recipientes durante os trabalhos de resgate emergencial do sítio arqueológico (Foto: Lima, 2010).

Outro sítio arqueológico, denominado Daisaku Ikeda, localiza-se muito próximo da área do sítio Lajes, a sudoeste deste. Situado dentro da área florestada pertencente ao Centro de Projetos e Estudos Ambientais do Amazonas (Cepeam), o sítio Daisaku Ikeda recebeu esse nome em função do então presidente da Associação Soka Gakkai Internacional (SGI). Durante as escavações para a instalação do Laboratório de Ciências Naturais da Associação foram resgatados dois artefatos: um gargalo de urna funerária e um alguidar de grandes dimensões.

Com uma privilegiada localização, defronte ao Encontro das Águas, Daisaku Ikeda aparenta ser contemporâneo ao primeiro, e provavelmente ocupado pelos mesmos grupos indígenas no passado. De fato, os vestígios enterrados, assim como a implantação no topo do terraço fluvial, remetem o sítio Daisaku Ikeda ao mesmo contexto de ocupação do sítio Lajes. Ao contrário de Lages, esse sítio encontra-se bastante preservado. No entanto, nunca foi alvo de estudos arqueológicos sistemáticos, tendo sido apenas cadastrado no Levantamento Arqueológico no Município de Manaus - Lama (COSTA e LIMA, 2006). Portanto, algumas das questões sobre as relações dos povos habitantes de Lajes e Daisaku Ikeda, ainda a serem estudadas, podem ser postas em pauta.

A grande vazante do rio Negro, ocorrida no final de 2010, evidenciou uma série de gravuras rupestres (petroglifos) na área conhecida como Ponta das Lajes. Esse afloramento rochoso, submerso na maior parte do ano, situa-se em frente aos sítios Lajes e Daisaku Ikeda. O sítio arqueológico, recentemente 
cadastrado no Iphan, apresenta centenas de bacias, cúpulas e sulcos de polimento, indicando intenso uso do local ao longo do tempo. As próprias gravuras, feitas em diferentes técnicas como o picoteamento e o polimento, recorrendo sempre à temática antropomorfa, indicam a importância simbólica do lugar para os povos do passado. As repercussões na mídia revelam também sua relevância para os povos do presente. Mais uma vez, a discussão remete ao tombamento da paisagem cultural composta pelo encontro dos rios Negro e Solimões, como instrumento legal de preservação, e à necessidade de ações que põem esse patrimônio em discussão junto à população manauara.

O sítio se localiza na margem esquerda do rio Negro, defronte ao Encontro das Águas, também no terreno do Cepeam situado no bairro Colônia Antônio Aleixo, zona leste da cidade de Manaus/AM. O sítio arqueológico assim chamado pela toponímia do local dada em razão da existência de uma "saliência de rochas silicificadas da Formação Alter do Chão cretácica, que se estende em direção ao centro do rio na base de uma falésia com cerca de $90 \mathrm{~m}$ de altura. A ponta está localizada no nível da água no período de seca, sendo encoberta pela água nas estações de chuva" (FRANZETTI e IGREJA, em: http://www.ig.unb.br/sigep/propostas/Ponta_das_Lajes_AM.htm).

Trata-se de um sítio arqueológico contendo inscrições rupestres do tipo petroglifo, em um afloramento arenítico sazonalmente exposto pela vazante do rio Negro. As gravuras rupestres foram executadas sobre blocos por meio de diferentes técnicas como a percussão e incisão. Os temas são, na maioria, antropomorfos (faces humanas), embora apareçam também figuras zoomorfas e geométricas. Além disso, bacias, estrias (sulcos) e cúpulas de polimento aparecem às centenas em toda a área do suporte rochoso, estimada em 5.000 $\mathrm{m}^{2}$ na ocasião da visita, em novembro de 2010. Em termos estilísticos, os motivos gravados se assemelham aos grafismos encontrados nos sítios Caretas e Ponta do Jauary (Itacoatiara/AM). Pensadas de forma integrada, "as lajes" podem ser consideradas como um importante componente da chamada (Figura 5 e 6) "paisagem cultural do encontro das águas", entre os rios Negro e Solimões. Dentre os potenciais impactos observados ao sítio arqueológico, estão a navegação fluvial sobre as rochas, vandalismo, além das intempéries naturais. 

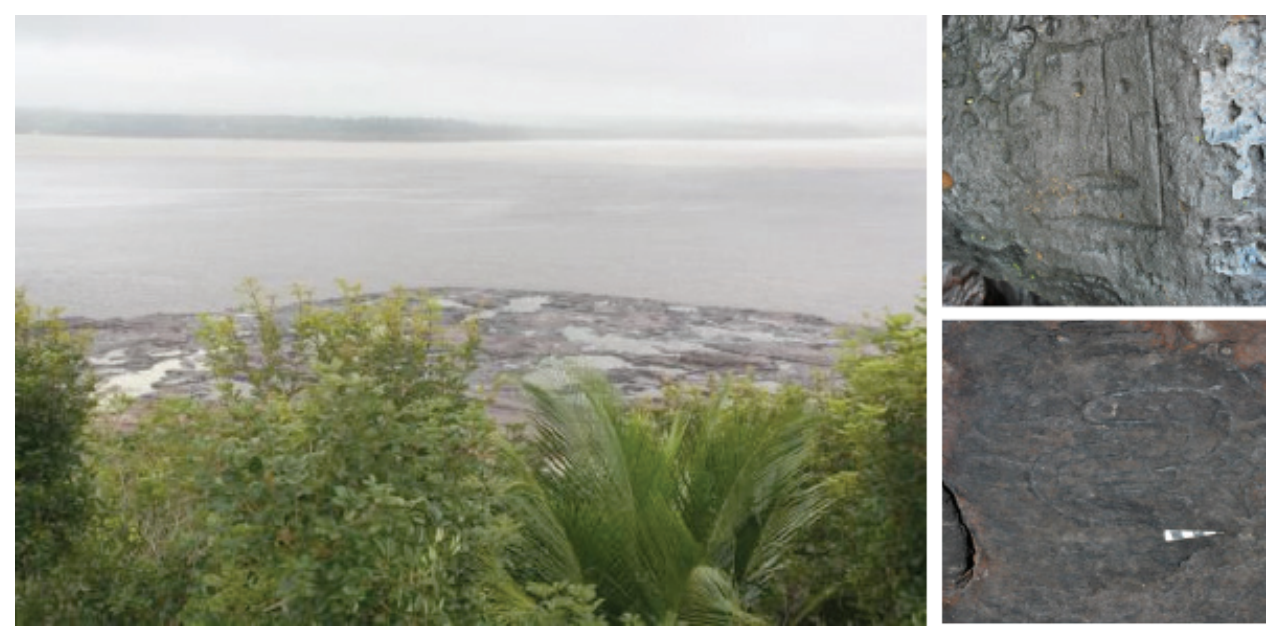

Figura 5 e 6 - Vista do sítio Ponta das Lajes a partir do sítio Daisaku Ikeda, petroglifos. (Fotos: Helena Lima, 2010).

Outra demanda por pesquisas arqueológicas se deu em maio de 2010, quando foi cadastrado o sítio Colônia Antônio Aleixo, que apresenta quantidade significativa de vestígios, entre eles dois grandes recipientes cerâmicos, aparentemente ligados à fase Paredão, aflorando em superfície. Como comumente acontece nos sítios arqueológicos localizados em área urbana, os vestígios se encontram bastante impactados por construções de edificações e arruamento da cidade, além das intempéries ambientais ocasionadas pela retirada da cobertura vegetal. Moradores do local (comunidade Onze) demandam o resgate das peças e das informações históricas nela contidas.

O sítio está implantado sobre um alto terraço com topo aplainado, defronte ao lago do Aleixo, na margem esquerda do rio Amazonas, nas proximidades do Encontro das Águas (confluência dos rios Negro e Solimões). O local é atualmente ocupado pela comunidade Onze, no bairro Colônia Antônio Aleixo, zona leste da cidade de Manaus/AM.

O sítio é formado por uma matriz sedimentar antropogênica - as Terras Pretas de Índio - que compõe a camada cultural em conjunto com cerâmicas arqueológicas em grande quantidade. As ocorrências arqueológicas são perceptíveis no terreno atualmente ocupado pela comunidade em duas áreas de concentração: uma primeira no local ocupado pelo campo de futebol e estacionamento, onde se observa a circunferência de dois recipientes aflorando, 
assim como grande quantidade de fragmentos cerâmicos espalhados em toda a superfície; a segunda área dista algumas dezenas de metros daquela e se encontra já bastante impactada por edificações e movimentação de solo, e se pode observar ali a circunferência de um recipiente cerâmico com diâmetro bastante grande, provavelmente superior a um metro. Nesse local já não há evidências de Terra Preta de Índio, o que sugere que esta tenha sido removida e que o vaso encontrava-se originalmente enterrado, numa camada inferior a esta. Há ainda informações de vasos retirados de outros locais, como da própria escola, que atualmente não são mais visíveis em função das construções.

A julgar pelos vestígios identificados na superfície do terreno, os materiais são relacionados à fase Paredão da Tradição Borda Incisa. Trata-se de alguns fragmentos com decoração plástica feita por incisões em linhas finas e motivos geométricos, bastante característico desse conjunto artefatual, e do recipiente de grande diâmetro. As grandes dimensões de (pelo menos um) dos recipientes identificados no sítio Colônia Antônio Aleixo pode sugerir tratar-se de um contexto funerário, também característico da fase Paredão, tal como já estudado em outros sítios na cidade de Manaus.

Conforme apontado nesta breve descrição das ocorrências arqueológicas no entorno do Encontro das Águas, a ocorrência de vários sítios arqueológicos nos bairros da zona leste de Manaus, particularmente na área que corresponde à ponta das Lajes (sítios Lages, Ponta das Lajes e Daisaku Ikeda) e o bairro Colônia Antônio Aleixo (sítio homônimo), está intimamente ligada ao próprio fenômeno do Encontro das Águas. Não por acaso, todos os sítios cerâmicos estão sobre terraços fluviais com terra preta, e possuem dimensões e densidade de material arqueológico consideráveis. Aliado ao fato da proximidade com os petroglifos presentes no sítio Ponta das Lajes - que demonstram uma clara apropriação simbólica do lugar pelas populações do passado - deixam entrever a importância do local, que se caracteriza como importante sítio arqueológico, geológico e ambiental da cidade de Manaus, e como parte da paisagem cultural do Encontro das Águas, atualmente em processo de tombamento pelo Iphan (Figura 7). 

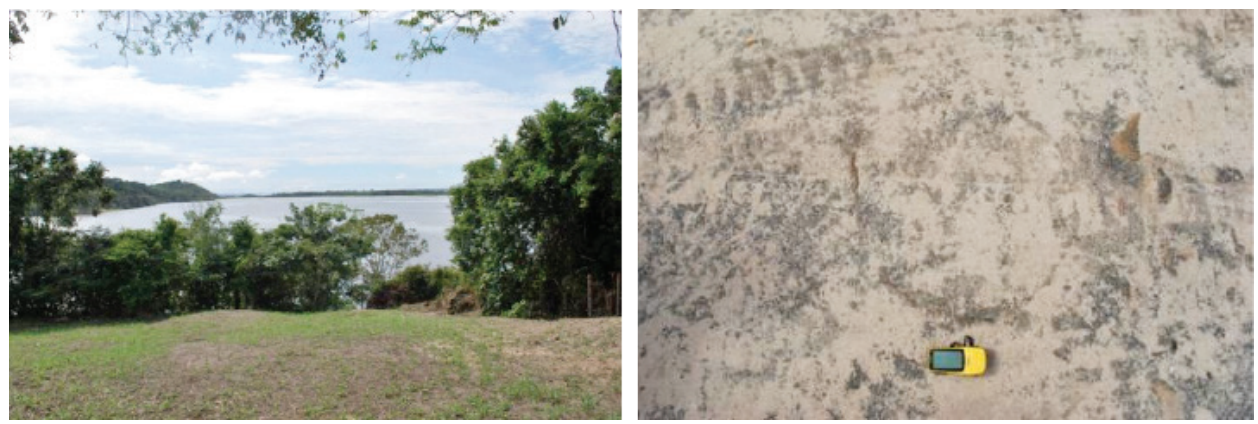

Figura 7 - Vista para o lago do Aleixo a partir do sítio arqueológico; recipiente cerâmico na superfície. (Fotos: Helena Lima, 2010).

As iniciativas formais de preservação do patrimônio arqueológico, préhistórico e histórico têm origem legal no Brasil com a Lei n. ${ }^{0} 3.924$, de 26 de julho de 1961. A partir de então, a defesa do patrimônio material das sociedades pretéritas passou a ser tratada no âmbito da legislação. A lei determina que todos os tipos de vestígios arqueológicos (lítico, cerâmico, faunístico etc.), que representem testemunhos de culturas passadas, são considerados patrimônio e, portanto, passiveis de tombamento. O texto legal indica que os monumentos arqueológicos ou pré-históricos existentes no território nacional ficam sob a guarda e proteção do Poder Público. Além disso, considera como sítios arqueológicos os locais com vestígios de ocupações paleoameríndias, tais como grutas, lapas e abrigos sob rocha; e locais como cemitérios, sepulturas ou aldeamentos, nos quais se encontram vestígios humanos de interesse arqueológico ou paleoetnográfico; as inscrições rupestres ou locais como sulcos de polimentos de utensilios e outros vestigios de atividade de paleoameríndias.

Grande parte dos sítios arqueológicos na Amazônia está comumente associada às áreas de ocorrência das Terras Pretas de Índio (que são muito férteis) em locais habitados até o presente, seja em contexto urbano ou por pequenas comunidades ribeirinhas. Assim, qualquer medida visando à proteção e preservação do patrimônio arqueológico da região deve necessariamente levar em consideração as significações dadas aos locais por parte de seus moradores, bem como os usos atuais dos terrenos. Vale lembrar, assim, que existe, por parte da comunidade civil organizada, uma forte demanda por estudos na área e que estes visam, em primeiro lugar, garantir a preservação do sítio arqueológico ali presente e de seus vestígios, assim como difundir informações sobre a história e o patrimônio cultural do local. 


\section{Referências}

COSTA, Fernando; LIMA, Helena. Levantamento Arqueológico no Município de Manaus. Relatório encaminhado ao Iphan, 1. Superintendência Regional. Manaus, 2006.

FRANZETTI e IGREJA. Disponível em: http://www.ig.unb.br/sigep/ propostas/Ponta_das_Lajes_AM.htm Acesso: 12/1/2009.

HILBERT, P. Archäologische Untersuchungen am Mittlern Amazonas. Berlin: Dietrich Reimer Verlag, 1968.

LIMA, Helena; NEVES, E. G; PETERSEN, James B. A Fase Açutuba: Um Novo Complexo Cerâmico na Amazônia Central. Arqueología Suramericana. Popayan - Colômbia, v. 2, n. ${ }^{\text {o } 1, ~ p . ~ 26-52, ~} 2006$.

LIMA, Helena; MORAES, Bruno. Avaliação de Impacto, Delimitação e Resgate Emergencial no Sítio Lajes - AM-MA-01. Relatório Final, encaminhado ao Iphan, Superintendência do Amazonas. Manaus, 2010.

LIMA, Helena; MORAES, Bruno. Produção de Conhecimento e Preservação em Debate: Aspectos da Arqueologia na Cidade de Manaus. Revista da Sociedade de Arqueologia Brasileira, v. 23, n. ${ }^{\circ}$ 1, 2010, p. 90-107.

NEVES, Eduardo. Ecology, Ceramic Chronology and Distribution, LongTerm History and Political Change in the Amazonian Floodplain. In: SILVERMANN, Helaine; WILLLIAM, Isbell (Orgs.). Handbook of South American Archaeology. New York: Springer, 2008, v., p. 359-379.

MEGGERS, Betty; EVANS, Clifford. An experimental Formulation of Horizon Styles in the Tropical Forest Area of South America. In: LOTHROP, Samuel (Ed.). Essays in Precolumbian Art and Archaeology. Cambridge: Harvard University, 1961.

Lowland South America and the Antilles. In: JENNINGS, Jesse (Ed.). Ancient South Americans. San Francisco: W. H. Freeman, 1983.

PETERSEN, James; NEVES, Eduardo; HECKENBERGER, Michael. Gift from the past: Terra Preta and Prehistoric Amerindian Occupation in Amazonia. In: MCEWAN, Colin; BARRETO, Cristina; NEVES, Eduardo 
(Eds.). Unknown Amazon, Culture in Nature in Ancient Brazil. London: British Museum, 2001.

RAMOS, Bernardo de Azevedo da Silva. Inscrições e Tradições da América PréHistórica: especialmente do Brasil. Rio de Janeiro: Imprensa Nacional, 1930, vol. I.

SIMÕES, M. Contribuição à arqueologia dos arredores do baixo rio Negro. In: Programa Nacional de Pesquisas Arqueológicas 5. Publicações Avulsas do Museu Paraense Emílio Goeldi, Belém, v. 26, 1974, p. 165-188.

SIMÕES, Mário; KALKMAN, Ana. Pesquisas arqueológicas no Médio Rio Negro (Amazonas). Revista de Arqueologia, v. 4, n. 1, 1987, p. 83-116.

SIMÕES, Mário Ferreira; COSTA, Fernanda Araújo. Áreas da Amazônia Legal Brasileira, para pesquisa e cadastro de sítios arqueológicos. Publicações Avulsas do Museu Paraense Emílio Goeldi, Belém, 1978, n. 30. 